Olivar, vol. 19, n 29, e052, mayo-octubre 2019. ISSN 1852-4478

Universidad Nacional de La Plata.

Facultad de Humanidades y Ciencias de la Educación.

Centro de Estudios de Teoría y Crítica Literaria

\title{
El futuro de la lengua, la lengua del futuro. Sobre la encuesta del diario Crítica (1927)
}

The future of the language, the language of the future. On the survey of the newspaper Crítica (1927)

Guillermo Toscano y García

Instituto de Lingüistica / Universidad de Buenos Aires,

Argentina

\section{Resumen:}

Este artículo aborda la encuesta que el diario argentino Crítica lleva a cabo en 1927 en relación con la posible existencia de un idioma argentino, a partir de la hipótesis de que esta funciona como un indicador del proceso de conformación de un campo científico para los estudios lingüísticos que se opera desde la creación, en 1922, del Instituto de Filología de la Universidad de Buenos Aires. Para ello, en primer lugar, busca reconstruir y analizar las posiciones establecidas por los participantes en la encuesta, que el diario organiza en dos grupos: las intervenciones no profesionales en el primero, las profesionales luego. A partir de lo anterior, concluye que el grado de profesionalización no es un buen predictor del tipo de intervención en el debate; y que las diferencias entre ambos grupos parecen estar vinculadas a los formatos argumentativos por los que optan y al grado de autonomía con que conciben el problema delimitado por la encuesta: si como esencialmente lingǘstico o literario.

Palabras ClaVE: Crítica, Encuesta, Idioma nacional, Amado Alonso, Américo Castro.

\section{Abstract:}

In this paper I analyze the survey carried out by the Argentine newspaper Crítica in 1927 on the possible existence of an Argentine language. The hypothesis I put forward here is that the referred survey functions as an indicator of the process of forming a scientific field for linguistic studies, operating since 1922 with the creation of the Institute of Philology at the University of Buenos Aires. I first seek to reconstruct and analyze the positions established by the participants in the survey, organized by the newspaper into two groups: non-professional interventions in the first place and then professional ones. Based on the above, I conclude that the degree of professionalization is not a good predictor of the type of intervention in the debate. Also, I conclude that the differences between both groups seem to be linked to the argumentative formats by which they opt in and to the degree of autonomy with which they conceive the problem delimited by the survey: as essentially a linguistic or a literary one.

KEYwORDS: Crítica, Survey, National language, Amado Alonso, Américo Castro.

El 11 de junio de 1927, el diario porteño Crítica inicia una encuesta que se propone obtener una

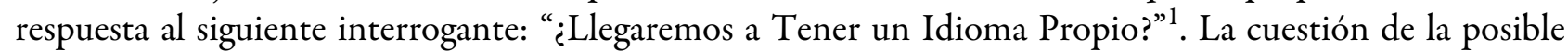
existencia de una lengua nacional, un idioma argentino distinto del español peninsular, emerge durante el siglo XIX y ocupa, como se sabe, el centro de los debates lingüísticos del siglo XX desde la publicación, en 1900, del texto de Lucien Abeille Idioma nacional de los argentinos. La crítica reciente (Alfón 2011; Ennis 2008 y 2017; Glozman y Lauría 2012, entre otros trabajos panorámicos) ha mostrado la riqueza de las intervenciones que, durante el primer cuarto del siglo pasado, buscan desde distintos formatos y en distintos ámbitos (la prensa periódica, pero también los debates educativos ${ }^{2}$ o políticos) posicionarse en relación con una pregunta que, ha sido advertido también, no solo inquiere respecto de la posible conformación de una lengua propia y distintiva sino que suele asociar a ella una valoración, una expectativa o un rechazo.

En particular, ha sido señalado (Di Tullio 2003; Toscano y García 2009) que la creación, en 1922, del Instituto de Filología de la Facultad de Filosofía y Letras de la Universidad de Buenos Aires supone un punto de inflexión en la tradición de esos debates, toda vez que implica para los estudios lingüísticos la emergencia de un campo disciplinar, un campo cientifico en términos de Bourdieu (2000 [1976]). La inauguración del Instituto (que se produce un año más tarde, en 1923), y la gestión de sus primeros directores, filólogos españoles designados por Ramón Menéndez Pidal en virtud de un acuerdo establecido con la Facultad de Filosofía y Letras, supone un proceso de fuerte reformulación del espacio destinado a los debates lingüísticos, en el que una paulatina distinción entre las intervenciones "profesionales" y las que no lo son empieza a 
constituirse en una medida de evaluación. Hemos examinado en otros trabajos (Toscano y García 2009, 2013) el modo en que los primeros directores españoles del Instituto (Américo Castro en 1923, Agustín Millares Carlo en 1924, Manuel de Montolíu en 1925 y, fundamentalmente, Amado Alonso entre 1927 y 1946) se posicionan, desde un saber que se pretende técnico y prestigiado por nuevos protocolos de legitimación, los de la ciencia filológica contemporánea, en contra de esa posibilidad de un idioma argentino; cómo, desde argumentos y saberes a los que reiteradamente caracterizan como "científicos", buscan mostrar que no es posible un proceso de cambio análogo al que llevó a la romanización del latín. A la vez, hemos investigado (Degiovanni y Toscano y García 2010a; Toscano y García 2013, 2015 y 2016) de qué modo, contemporáneamente a este proceso de conformación de un campo científico, se posicionan un conjunto de figuras que resultan desplazadas por quienes pasan a detentar el monopolio de la autoridad científica: Jorge Luis Borges, Arturo Costa Álvarez, Delfina Molina y Vedia de Bastianini y Vicente Rossi son las voces más destacadas entre aquellas que sostienen posiciones alternativas y críticas a las de los filólogos españoles, lo que sin embargo no necesariamente implica que, como en el caso de Costa Álvarez, acepten la hipótesis de una futura lengua nacional.

En este marco, 1927 es una fecha clave en la historia de los debates lingüísticos. También aquí la crítica ha reconstruido la densidad que, durante ese año, adquiere la discusión respecto de la posible existencia de una lengua propia de los argentinos. En una rápida reseña, puede recordarse que durante este año Guillermo de Torre escribe en La Gaceta Literaria que Madrid es el "meridiano intelectual de Hispano-América", afirmación que genera un conjunto de rechazos y burlas por parte del periódico de vanguardia Martín Fierro; en 1927 también Jorge Luis Borges lee, por intermedio de su amigo Manuel Rojas Silveyra, la conferencia "El idioma de los argentinos" en el Instituto Popular de Conferencias de La Prensa; es entonces cuando uno de los más conspicuos críticos del Instituto de Filología, Vicente Rossi, inicia la serie de los Folletos lenguaraces que publicará hasta 1945. Estas discusiones tienen a menudo a la prensa periódica como espacio recurrente y privilegiado; así lo muestra Alfón (véase Alfón 2011 para un registro detallado de las intervenciones durante este año), quien luego de revisar un conjunto de textos publicados durante 1927 en el diario La Nación, concluye señalando el peso que las discusiones lingüísticas tienen para este diario:

Estas son algunas de las notas con que diariamente La Nación mantenía la querella en perfecto estado de salud. Esta década del 20, sobre todo, es en la que el diario se muestra más entusiasta con ella, y un relevamiento exhaustivo de ese entusiasmo podría componer un capítulo aún mucho más vasto. (2011: 196)

El de 1927 es, finalmente, el año cuando asume como director del Instituto de Filología Amado Alonso, su más destacado director. Las fechas, en este caso, son relevantes: el contrato entre Alonso y la Facultad de Filosofía y Letras se firma el 20 de septiembre de 1927 (Archivos de la Universidad de Buenos Aires 1927: 440), es decir casi tres meses después de terminada la encuesta de Crítica: es posiblemente esta la razón por la que, si la encuesta es contemporánea de un proceso de profesionalización, al mismo tiempo parecen faltar en ella los profesionales de la lengua agrupados en el Instituto de Filología. Esta ausencia explica un aspecto decisivo en el recorrido que proponemos: si bien la encuesta se desarrolla entre el 11 y el 29 de junio de 1927, existe una coda, una continuación tardía que tiene lugar los días 25 y 26 de septiembre. En esta coda, el diario retoma el tema de la encuesta a través de dos textos vinculados a los filólogos españoles: en el primero, decide responder a un artículo publicado por Américo Castro en La Nación una semana antes, el 18 de septiembre de 1927; en el segundo y último de la serie, da la palabra a Amado Alonso, quien en una de sus primeras intervenciones públicas en el país al que acaba de llegar se pronuncia contra la posible existencia de un idioma argentino y pretende así clausurar el debate. Las posiciones que Alonso expresa, a las que pretende como decíamos investir del prestigio de la moderna ciencia lingüística, son al mismo tiempo que reconocidas en ese sentido por el diario una variable de contraste respecto de quienes intervienen antes que él. Leer la encuesta de Crítica como un signo de ese proceso de conformación de un campo científico, reconstruir las variantes 
que esos actores que no son ya profesionales de la lengua y contrastarlas con las de quienes ocupan ese lugar es, entonces, el objetivo que nos proponemos para este trabajo.

La encuesta de Crítica se organiza entonces en dos partes: un bloque principal y lo que hemos llamado coda. En el primer bloque, se registran las siguientes intervenciones:

Sábado 11 de junio de 1927: Enrique Larreta, p. 7.

Domingo 12 de junio de 1927: José Antonio Saldías, p. 7.

Lunes 13 de junio de 1927: Ricardo Rojas, p. 6.

Martes 14 de junio de 1927: Víctor Mercante, p. 9.

Jueves 16 de junio de 1927: Last Reason, p. 3.

Viernes 17 de junio de 1927: Roberto Payró, p. 9.

Sábado 18 de junio de 1927: Félix Lima, p. 17.

Domingo 19 de junio de 1927: Jorge Luis Borges, p. 3.

Lunes 20 de junio de 1927: Manuel Gálvez, p. 6.

Martes 21 de junio de 1927: Enrique García Velloso, p. 9.

Miércoles 22 de junio de 1927: Arturo Costa Álvarez, p. 7.

Jueves 23 de junio de 1927: Alberto Nin Frías, p. 10.

Viernes 24 de junio de 1927: Arturo Cancela, p. 9.

Sábado 25 de junio de 1927: Alberto Gerchunoff, p. 6.

Domingo 26 de junio de 1927: José María Monner Sans, p. 2.

Lunes 27 de junio de 1927: Florencio Garrigos (hijo), p. 12.

Miércoles 29 de junio de 1927: nota editorial de cierre, p. $7^{3}$.

En la coda, las siguientes:

Domingo 25 de septiembre de 1927: "La encuesta de Crítica: ¿Llegaremos a tener idioma propio? y D. Américo Castro", p. 16.

Lunes 26 de septiembre de 1927: "En Buenos Aires se habla bien el español. El diario, el libro y el puerto son enemigos del lunfardo, nos dice el filólogo español Amado Alonso”, p. 5.

Se trata entonces de una serie de 16 entrevistados, seguida por una nota editorial a modo de balance y conclusión; se agregan luego una segunda nota editorial y una nueva intervención, la de Amado Alonso.

Oliveto (2014: 114-115) analiza la composición del grupo de entrevistados; señala la ausencia de colaboradores habituales del diario, así como de algunos escritores que, sostiene, podrían haber respondido desde una diferente posición estética:

[...] en su mayoría, quienes responden no son los martinfierristas que formaban parte del staff del diario. De la llamada Nueva Generación, sólo interviene Jorge Luis Borges. Y también se puede mencionar a Arturo Cancela, escritor cercano al martinfierrismo. Tampoco se registran intervenciones de los escritores de izquierda, enemigos acérrimos del diario. La encuesta consulta a personalidades cuya centralidad en el campo literario es notoria: Enrique Larreta, Ricardo Rojas, Roberto Payró, Alberto Gerchunoff, entre otros. Llama la atención la ausencia de aquellos escritores que, trabajando para Crítica en ese momento, elaboran su literatura a partir de la utilización de un lenguaje potente y heterogéneo. Nos referimos, por ejemplo, a Roberto Arlt [...]. Otro caso es el de Nicolás Olivari, [...] o el de Enrique González Tuñón y Carlos de la Púa [...]

Desde nuestro punto de vista, interesa destacar que los participantes de la encuesta parecen tener en común el hecho de que no son, en un contexto en el que esa figura ya ha aparecido, profesionales de la lengua; si bien es cierto que intervienen figuras claramente vinculadas a la academia, tal el caso de Ricardo Rojas, esa 
vinculación no es suficiente ya para acreditar una especificidad disciplinar. Los entrevistados son escritores (en su mayoría), pedagogos, periodistas; posibles excepciones como la de Costa Álvarez son, como veremos, en verdad confirmaciones de que quienes responden a la encuesta de Crítica lo hacen desde un lugar que ya no es percibido como el del experto. Así lo marcan, de hecho, las presentaciones que el diario va haciendo, que tienden a registrar los méritos que los entrevistados poseen pero que han adquirido en un dominio que ya no es el de la práctica científica académica.

Así se percibe ya en la primera de las intervenciones en el debate, la de Enrique Larreta: de él se dice que es "una de las personalidades literarias de mayor enjundia". La presencia inaugural de Larreta parece ilustrar ejemplarmente el análisis de Oliveto (2014), para quien tanto los entrevistados por Crítica como la conclusión de la encuesta contrarían las posiciones idiomáticas sostenidas hasta entonces por el diario. Es evidente que Larreta, una figura largamente comprometida con la proyección y continuidad del hispanismo en el país, representa posiciones conservadoras en relación con el cambio lingüístico.

No obstante, el tipo de intervención que llevan a cabo los escritores no es uniforme. Como veremos, parecen registrarse al menos dos tipos de respuesta: por un lado, la de aquellos que adoptan el criterio de que el problema de la lengua en la Argentina es un problema estético y establecen una valoración o una programática de carácter claramente literario: la figura emblemática de esta posición, aquí y en el período, es la de Borges. Por su parte, otro conjunto de escritores, sin descartar por completo el aspecto literario, intentan una intervención que aspira a participar de los debates más claramente lingüísticos del período: ese uso, que a menudo es un uso extrañado, de las teorías científicas anteriores y contemporáneas está por ejemplo expresado por posiciones como las de Gálvez y la del propio Larreta.

El punto de partida de Larreta es el establecimiento de una comparación recurrente en el período, la que se establece entre la romanización del latín y el español en América. Su enfoque repite de algún modo los criterios disciplinares, por ejemplo las posiciones establecidas por Menéndez Pidal (1918), según las cuales las condiciones históricas, y en particular el surgimiento de eficaces sistemas de comunicación a gran escala, inhiben la posibilidad de que el español sufra el mismo proceso de cambio que el latín:

Me parece que han pasado los tiempos de la formación de idiomas nuevos. Debe haber en esto una ley parecida a la que ha regido la formación de las especies vivas. Comprendo que puede haber modificaciones, las unas favorables, que acrecen verdaderamente la fuerza expresiva, la eficacia de una lengua y otras que la bastardean, la envilecen, la destruyen. Hoy día, dada la facilidad de las comunicaciones es más difícil que un idioma se transforme por completo, como sucedió con el latín en España y en las Galias después de la caída del imperio 5 .

El segundo de los argumentos propuestos por Larreta para impugnar la posible formación de una lengua propia abreva en otra tradición argumentativa, la de la propiedad de la lengua, tema sobre el que Ennis (2014, 2015) ha trabajado detenidamente. De modo relativamente inesperado, Larreta sostiene que la propiedad de la lengua la tiene "el pueblo"; concretamente, señala: "Creo que la suprema autoridad aunque esto parece una declaración indigna de un escritor, en materia de idiomas, es el pueblo". En su perspectiva, "pueblo" equivale a "lengua vulgar": al pueblo pertenecen los "modismos", las "locuciones"; la lengua culta es estable y la vulgar dinámica, como queda claro en la otra cita: "Yo mismo viajando por España he aprendido muy poco en materia de lenguaje en los círculos aristocráticos. En cambio en las carreteras, en los poblados, en los campos, qué de sorpresas, qué de adquisiciones magníficas".

La estratificación a la que apela Larreta tiene ya en 1927 una consolidada tradición en la ciencia filológica, y en particular en las intervenciones debidas a Menéndez Pidal y a los integrantes del Centro de Estudios Históricos que dirige desde 1910 (Toscano y García 2005). En la lógica de Menéndez Pidal, la lengua vulgar es por naturaleza dinámica; por el contrario, la culta tiende a la estabilidad y a la permanencia. La romanización del latín se explica en parte en esta clave: debilitada por su expansión geográfica, el habla de los sectores cultos no consigue limitar la naturaleza rupturista de la vulgar; la hipótesis hace equivaler así el cambio lingüístico a la pérdida de la jerarquía social, una perspectiva que será largamente productiva en el trabajo de quien es posiblemente el más agudo representante de esta hipótesis sociológica e histórica, Américo Castro (1941). 
La posición de Larreta en la encuesta abona esa igualación de jerarquía social y orden lingüístico, pero lo hace desde un punto de partida singular que parece contradecir lo anterior: "En nuestro país, los que ayudan a conservar la riqueza y la pureza de la lengua, son los sirvientes españoles”. Invirtiendo la lógica que acababa de establecer, Larreta apela a una suerte de economía política de las lenguas como criterio y, alejándose de lo que el discurso especializado venía construyendo en ese sentido, sostiene que la riqueza y la pureza de la lengua están en el pueblo, y que la lengua vulgar es conservadora: "La criada de la península que enseña vocablos y giros a la señora criolla, el mucamo castellano o andaluz que instruye idiomáticamente al señor y a los niños más o menos lunfardizantes. Son la gramática viva y el diccionario fácil”. Su explicación es también una reinterpretación del tópico de la propiedad de la lengua: aquí Larreta asocia propiedad lingüística a desposesión económica, y al revés: el rico es el que habla impropiamente.

José Antonio Saldías, otro escritor, es el segundo entrevistado de la encuesta. Su intervención, a pesar de que repite algunos de los argumentos de Larreta, incorpora otros nuevos al debate. Para Saldías, la conformación de una sociedad nueva como la argentina va necesariamente aparejada a un fenómeno de innovación lingüística: "La composición de la nueva raza de la Argentina del presente y del mañana, es factor determinante en la adopción de giros, vocablos y expresiones que, aun cuando la Academia Española no acepte, están en uso permanente". Como para Larreta, esa creatividad lingüística parece darse en el nivel léxico; no es un dato menor que, para casi todos los entrevistados, "idioma propio" es más o menos explícitamente un conjunto relativamente inespecificado de ítems léxicos. Sin embargo, y este es un rasgo que distingue la posición de Saldías, para él la variación ocurre también en el nivel morfosintáctico: así por ejemplo agrega que ese diferente ánimo expresivo de los argentinos "ha hecho, por ejemplo que alteremos la acentuación en el tuteo así como que empleemos un pronombre personal que en esencia y significado no existe en el idioma madre".

La crítica de la Real Academia Española como institución reguladora de las formas lingüísticas legítimas también es un tópico entre las respuestas a la encuesta de Crítica. Aquí Saldías sostiene, como será una constante entre la mayor parte de los entrevistados, un antiacademicismo moderado, toda vez que opta antes por el desconocimiento que por la polémica: la variación del español en la Argentina, dice, es un fenómeno "que la Academia no tendrá jamás en cuenta y nosotros seguiremos usando, incurriendo en pecado de 'mal hablar"”; luego agrega:

[...] esa oficialización no es necesaria. El pueblo mismo, necesitado de expresar espontánea y llanamente lo que piensa irá haciendo el idioma, enriqueciéndolo poco a poco y día llegará en que leeremos muchos libros de gran interés general, escritos con la sencillez y la fuerza expresiva característica de nuestra modalidad.

Para Saldías, "pueblo" no parece ser, como para Larreta, un concepto restringido, es decir, la lengua del pueblo parece ser la de todos los argentinos, no la lengua vulgar. Para él, es el pueblo con sus usos el que tiene la propiedad de la lengua: "Y qué importará entonces la sanción oficial, si el uso, la costumbre lo ha difundido entre el pueblo, lo ha hecho ley?". Pero el concepto de "propiedad” es para Saldías todavía más productivo: así luego, al referirse a la lengua del teatro nacional, dirá que "las obras teatrales deben ser ante todo 'bien habladas", e indicará qué entiende por ello: "Y al decir 'bien habladas' me refiero a la propiedad de lenguaje de los personajes, de acuerdo con su origen, condición, educación, psicología, profesión, medio en que viven y pasiones que los desplazan”. Tres alcances entonces de la propiedad lingüística: el pueblo propietario de la lengua con sus usos, pero también "propiedad de lenguaje" como capacidad del dramaturgo para representar fielmente las dialectos particulares; pero, todavía, un "escribir con propiedad", que sería un uso más general de las formas literarias. Así, denuncia que cierta forma de la literatura demagógica consistiría puramente en incluir estos elementos típicos: "Esa condición esencial de nuestro teatro hace que no sea imprescindible saber escribir con propiedad para confeccionar una obra de éxito popular”.

Otro tópico que la respuesta de Saldías introduce en la encuesta, y que sumará acuerdos mayoritarios entre las respuestas que siguen, es la afirmación de que esa "modalidad" argentina es algo bien distinto del lunfardo, 
que resulta caracterizado negativamente: "No se crea por todo lo expuesto que yo propicio la adopción o incorporación del 'lunfardo'. Muy por el contrario. Por conocer ese 'vocabulario' sé que carece de alcurnia suficiente para expresar la belleza que enseña a amar a un idioma”.

El último de los tópicos es la reinterpretación de la cuestión del "idioma nacional” en términos de intervención estética. Anticipando una posición que tendrá su realización más destacada en la intervención de Borges pero que como dijimos se registra en una gran cantidad de encuestados, aquí Saldías hace evidente que lo que se impugna es un cierto uso de la lengua literaria, y que el adversario es otro grupo de escritores, los "tradicionalistas fanáticos":

Los opositores al idioma nacional, tradicionalistas fanáticos, escritores en general lamidos y poco espontáneos, de vocabularios cuya riqueza es un tanto pasada de moda, no podrán ejercitarse en una campaña contra una generación movediza y pujante de escritores inquietos, que se buscan a sí mismos en la sencillez y se encuentran en la batalla contra lo rígido, lo establecido, lo tradicionalmente cristalizado.

La proximidad con las posiciones que luego expresará Borges en la encuesta se verifica, finalmente, en la postulación de que la eventual conformación de un idioma argentino será un fenómeno futuro; como para Borges, una vez más, esa posibilidad futura es una búsqueda estética equidistante de los excesos de los "tradicionalistas fanáticos" pero también de "los bastardeos del analfabetismo que 'sabe leer", una referencia indudable a cierto tipo de literatura arrabalera y próxima al "lunfardo llorón y sentimental".

La presencia de Ricardo Rojas introduce en la encuesta la figura del académico. Sin embargo, como anticipamos, esa investidura no posiciona a Rojas en el lugar del saber experto; su mirada no es la del profesional de la lengua sino, y así lo destaca la presentación que hace Crítica, la de un "historiador de la literatura argentina, ensayista de relieve y creador de obra vasta y rica en sabias sugestiones". Ese lugar singular que sin embargo Rojas detenta en virtud de su pertenencia universitaria parece explicar el hecho de que sea el único de los entrevistados que interviene bajo el formato textual de una entrevista.

La intervención de Rojas (de abierto rechazo) constituye un recurso a lo que estima como argumentación científica; en realidad, el recurso a la ciencia le permite a Rojas validar una intervención que es también política:

$-¿$ Cree usted que se está formando un idioma argentino?

- En la elucidación del problema que usted me propone suelen inducir en error dos prejuicios: el primero, de psicología nacional, el segundo, de interpretación histórica. El prejuicio de psicología nacional consiste en el error de creer que no seremos una nación completa, sino cuando tengamos un idioma propio. El prejuicio de interpretación histórica consiste en el error de creer que así como del latín se derivó el castellano, del castellano se derivará el "argentino".

Una vez hecha esta aclaración le digo sin ambages que no creo en la formación de un idioma argentino y que, además, no la deseo porque sería pernicioso para nuestra civilización.

El argumento científico, que Rojas llama "de interpretación histórica”, constituye una ampliación de la analogía con el latín que ya aparecía en la respuesta de Larreta. Después de revisar las condiciones que hicieron posible la romanización del latín, declara que las condiciones históricas son de bien distinta naturaleza, por lo que el fenómeno no podrá repetirse; su argumento, que hasta aquí no innova respecto de las respuestas anteriores, introduce sin embargo un elemento novedoso, que es la pregunta respecto del papel de los inmigrantes en la potencial ruptura de la unidad lingüística entre España y la Argentina. Rojas rechaza el potencial disgregatorio de la inmigración, y busca mostrar una sociedad controlada, en la que la enseñanza de la lengua a los hijos de los extranjeros, pero también la práctica literaria y la de "las fuerzas políticas y morales de nuestro país" contribuyen al mantenimiento del español peninsular, fuerza cohesionadora de americanos y españoles:

La lengua castellana continúa en su vigor de autoridad oficial y de función cultural, aun más eficazmente que en tiempo de la colonia española. Los principales escritores argentinos, como Larreta y Lugones, la cultivan con amor filial. Las escuelas populares y las escuelas del ejército les enseñan el castellano a los hijos de la inmigración cosmopolita y ya han florecido de esa sangre nuevos escritores muy castizos con nombre extranjero. Todo esto prueba que las fuerzas políticas y morales de 
nuestro país trabajan por el mantenimiento del idioma histórico, que nos liga a nuestro propio origen como nación, al resto de América en la fraternidad de ochenta millones de hombres que hablan el mismo idioma, y a España, que es la patria del Quijote, en nombre del cual podemos reclamar nuestra hijuela en el patrimonio común de la cultura europea y de sus fuentes clásicas.

La conveniencia de la unidad lingüística es otro de los tópicos de la encuesta; dice Rojas que, para los argentinos, es cuestión de "la mayor importancia política y de la mayor ventaja comercial"; esto es, "todos los pueblos que hablan castellano podrán mañana ser mercado para los viajantes de comercio que también lo hablen y lectores en quienes resuene directamente la voz argentina de nuestros filósofos y de nuestros poetas".

En cuanto a la variación lingüística, Rojas reconoce su existencia, y la ubica primero (como sus colegas antes) en el plano de la intervención estética. El castellano, dice, puede transformarse, "por la asimilación de nuevas voces, por la creación de nuevos significados, por la invención de nuevos giros, ritmos y formas estéticas", con el objetivo de "dar color a la pintura de ambientes regionales".

No obstante, esa variación estilística no implica la existencia de una lengua diferente; como todos los entrevistados hasta aquí, Rojas abona al rechazo del lunfardo como encarnación y emblema de esa posible identidad lingüística:

Es lamentable que se confunda todo esto con la floración efímera y cambiante del argot popular, que existe en todas las grandes ciudades y mucho más en los grandes puertos cosmopolitas. Esta habla del suburbio y del bajo fondo policial, aunque pase al sainete y a la prensa burlesca, no tiene más consistencia que la de esos pequeños hongos que proliferan en las tierras húmedas debajo de grandes Rocas.

La participación de Víctor Mercante, a quien se presenta como "Pedagogo de tendencias modernas y sociólogo de nota", cierra este grupo de intervenciones que parecen caracterizarse por su mayor densidad conceptual. También Mercante rechaza la posible formación de un idioma argentino; los argumentos que presenta son, sin embargo, relativamente novedosos. Por una parte, es el único de los entrevistados que alude a las lenguas indígenas habladas en el país; lo hace a partir de una valoración limitada y declarándolas desaparecidas, pero la suya es la única intervención que traza un horizonte lingüístico en el territorio nacional donde no solo conviven el español y las lenguas inmigratorias:

La oportunidad de un idioma propio ha pasado. El quechua y el guaraní, al faltarles una literatura que impusiera su vocabulario, su sintaxis y sus bellezas fonéticas, son lenguas que, desgraciadamente, han muerto alimentando, con sus despojos, el castellano, renovado y robustecido siglo tras siglo, merced a su vitalidad extraordinaria.

Si para Rojas la escuela jugaba un rol central en el mantenimiento de la unidad lingüística bajo el castellano peninsular, Mercante lleva al paroxismo esa percepción del lugar de la institución escolar y, por analogía con lo que había esbozado para las lenguas indígenas, señala que esta es el instrumento de "reducción cultural" con el que el castellano somete a las lenguas inmigratorias:

Pero el siglo XX dispone de una guardia palatina formidable, la escuela popular que impide que dentro del idioma cuajen formas que habrían de traer, como ocurrió con el latín, la proliferación regional. La escuela común que impuso el italiano en la península de los dialectos no solamente limpia, en América, de voces extrañas al castellano sino que vela por su pureza, su pronunciación, el uso correcto de los términos y la belleza de la oración. Gracias a nuestra ley previsora de educación, se apodera del niño no bien cumple los siete años y lo somete desde el primer día de clases, a un tratamiento gramatical tan intenso como eficaz. A los tres años desparece la mayor parte de los barbarismos; la fonética pierde la acentuación extranjera y la sintaxis, sus construcciones arrevesadas. El censo escolar arroja en Buenos Aires, solamente el 2\% de analfabetos. La reducción cultural es completa. Mi creencia es que, en adelante, es imposible que nazcan nuevos idiomas [...].

La afirmación de Mercante de alguna manera completa el círculo abierto por Larreta en relación con la propiedad de la lengua, indicando la modalidad de esa relación. Para Mercante, es la lengua legítima la que se apodera del hablante a través de la institución escolar, que lo "somete" a un "tratamiento gramatical" como consecuencia del cual, celebra, el hijo de inmigrante sufre la pérdida de su lengua y adopta una nueva. 
Por otro lado, mientras que los anteriores entrevistados se preguntaban (y rechazaban) la posibilidad de que el lunfardo fuera evidencia de un futuro idioma propio, Mercante examina el caso del gauchesco, y tanto observa criteriosamente que esa lengua literaria es un cierto tipo de español, no una lengua distinta; como utiliza una categoría, la de "dialecto", en el sentido de "protolengua", un uso ya impropio en el campo científico contemporáneo, pese a que filólogos como Castro todavía lo mantienen en 1923:

El "Martín Fierro", es un monumento literario. Pero su lenguaje, dentro de las normas históricas de un idioma, no alcanza a ser un dialecto. Su gramática es castellana y castellano el léxico [...]. Las alteraciones desinenciales, la elisión, el apócope cuando no modifican el concepto no bastan para fijar un nuevo idioma.

El párrafo final de su intervención lo dedica Mercante a evaluar una hipótesis que de alguna forma es el contrario dialéctico de la que propone la encuesta: contra la disgregación, registra la posibilidad misma de la unificación bajo una única lengua, una suerte de proceso de re-romanización debido otra vez a la acción de la escuela:

Es posible, en razón de la estructura análoga, que los idiomas de origen latino - tal vez influenciados por el latín-en contacto más íntimo hoy que antes, constituyan una sola lengua. En las escuelas americanas se estudian los tres idiomas y el cerebro acepta fácilmente tres o cuatro mil términos de cada uno.

La intervención de Last Reason es anticipada positivamente por el diario, que dice de él que "encontró matices insospechados e infundió nueva vida al pintoresco idioma. Hoy, con el extinto Fray Mocho y Félix Lima forma la trilogía de lo que podríamos llamar 'clásicos del lunfardo"'.

A diferencia de las anteriores, su respuesta es favorable a la existencia de esa nueva lengua; su intervención es, de hecho, un ejercicio de estilo en el que utiliza todo el tiempo el "idioma argentino" cuya existencia pregona: "Vea compadre, el idioma argentino existe; usted lo conoce, lo manya desde pibe, lo chamuya a ciertas horas y lo oye chamuyar desde el pique hasta la raya".

Para evidenciar la existencia de este idioma, Last Reason procede primero a rechazar el argumento introducido por quienes lo anteceden en la encuesta: el idioma argentino no es una forma patibularia, algo que sin embargo intelectuales como Larreta o Rojas no pueden percibir: "los bacanes no van a admitir de ningún modo que la parla nuestra sea otra cosa que una simple compadrada nacida en el suburbio y repetida por farra en el asfalto".

La larga argumentación a continuación permite ver con claridad que lo que Last Reason coloca como evidencia de una lengua propia es en verdad una variedad. Dice de esa posible lengua, primero, que "el idioma, aun sin bautizar que sirve para el intercambio de las ideas espontáneas y que se usa para expresar de viva voz lo que sentimos, ese idioma existe sensa grupo". Y luego:

Porque, ¡hay que embromarse! cuando un criollo cacha la de ganso y se pone a batirle sobre el pelpa sus calores a la mina, o cuando se quiere hacer el rana en los periódicos, entonces sí, se prende al castellano y echa mano a su bagaje del colegio. Pero póngase delante del hombre desnudo, del tipo tal cual es, del macho ejerciendo sus funciones, cascándose o escolasándose la guita, o batiendo al oído de la mina berretines o rechiflamientos... y entonces vamos a ver adonde queda lo aprendido en las escuelas e institutos... Entonces jupa guapo! el espíritu criollo voltea de un sopapo al monigote castellano que nos sirve de intérprete cuando la vamos de finolis, y sacando pecho se alza y... bate, chamuya, parla, eso que todavía es un mamarracho arbitrario y detonante, pero que tiene en sí savia de vida porque es el producto de la propia davi.

Para demostrar la existencia de esa lengua propia, Last Reason muestra que su uso convive con el del "monigote castellano" y que la distribución es situacional. Sus ejemplos evidencian sin embargo que la alternancia no es entre lenguas sino entre variedades de una misma lengua, cuyos rasgos distintos (fonéticos, morfosintácticos y léxicos) Last Reason registra acertadamente:

Cuando Ricardo Rojas siente el berretín de un amorcito, ¿susurrará a la pebeta “iQué hermosa eres doncella”, o le batirá el justo chamuyándole en la oreja... ¡Qué macanuda estás, che papirusa! ...? Don Larreta, al perder un pozo grande con full de ases servido, ¿exclamará un castizo “iMala suerte, vive Dios!”, o tirará la bronca con un ¡Mecach’endié que mala pata!? 
Y los doctos bacanes que han dicho pestes del lenguaje suburbano, ¿pronunciarían la ce, la zeta y la elle cuando digan "En la tercera los escandaliza mi caballo"?

Las intervenciones de Roberto Payró y Félix Lima reintroducen en líneas generales los tópicos que hemos identificado. Se trata en ambos casos de respuestas negativas al interrogante planteado por la encuesta; las argumentaciones, no obstante, trazan diferentes recorridos.

Para Payró, la explicación es esencialmente histórica: no hay condiciones históricas análogas a las que permitieron la romanización del latín. La continuidad del contacto entre España y sus colonias funcionó para Payró como un freno a ese potencial de fragmentación; también en este caso, la explicación histórica va asociada a una valoración de carácter geopolítico: "Si hubiéramos permanecido aislados de España y de Europa en general, la formación de un idioma propio hubiese sido posible. Y aun así, en nada nos favorecería, ya que tendríamos necesidad de una lengua auxiliar".

Payró, como varios de los entrevistados antes, registra como un hecho positivo que la Academia se muestre más propicia a la adopción de voces propias: "España está advirtiendo la necesidad de incorporar al vocabulario voces típicamente criollas". Como todos los entrevistados, también, rechaza que el lunfardo sea una lengua, aunque la igualación de un léxico especializado con lenguas indígenas como el quichua y el guaraní resulta largamente cuestionable:

En cuanto al habla callejera, en el lapso de tiempo que llevo vivido, he observado que varía. Si yo escribiera con el lunfardo de cuando era niño, los arrabaleros de hoy no me comprenderían. Son términos transitorios, si bien algunos quedan definitivamente incorporados al idioma.

Los pequeños idiomas que hablaban en el país los aborígenes tienden a desaparecer cuando no han desaparecido ya. Es lo que ocurre con el quichua y el guaraní, que sobreviven precariamente y morirán cuando mayor sea el contacto de unas provincias y regiones sobre otras, lo que propiciará la unificación total del castellano en todo el territorio del país.

Finalmente, coloca la pretensión de un idioma propio en el terreno de la travesura infantil, un argumento abiertamente descalificatorio de las posiciones que reivindican contemporáneamente la posibilidad de una emancipación lingüística: "La aspiración nuestra a un idioma nacional, si la tuviéramos, sería como la de los chicos traviesos que tratan de hablar en jeringoza para entenderse sólo entre ellos, en sus picardías".

La presentación de Lima como un exitoso difusor del "argot" porteño permitiría esperar una respuesta favorable en la encuesta; sin embargo, como dijimos, su posición es en general negativa.

Su argumento ofrece algunas características distintas. Por una parte, acude a una comparación infrecuente entre los entrevistados: para él, tal como sucede con el inglés, el léxico adquiere rasgos específicos en cada país: “a fuerza de enriquecerse, el léxico aquí, un peninsular, arropado de casticismo terminará por no comprenderlos exactamente como sucede con los ingleses que a veces se ven en figurillas para interpretar a un yanqui". Lima pone claramente en el léxico ese punto de desencuentro; no son dos idiomas diferentes, dice, sino unas palabras que no serán intercomprensibles.

Lima encuentra en la inmigración, los deportes y la cocina las principales causas de enriquecimiento léxico. El resultado es un habla de "acentuadas características propias": el siguiente fragmento muestra el grado de dispersión de las categorías: Lima empieza refieriéndose a una "lengua", luego a un "argot" y finalmente a las "palabras arrabaleras":

Familiarmente hablamos ya una lengua con acentuadas características propias, lo que no es una singularidad del vulgo tan solo. La gente distinguida suele hablar también en argot con bastante frecuencia y en deliciosas bocas de criaturas todo lo linajudas que puede permitirlo nuestra sociedad de ganaderos, se oye, en el ferrocarril, en cines, en teatros, en reuniones, clubs y calles palabras arrabaleras de moda.

Esa lengua familiar, asimilable a una variedad del español, no derivará en el surgimiento de una lengua diferenciada, una posibilidad que Lima rechaza apelando también él al argumento de la unidad lingüística:

La intervención de Jorge Luis Borges destaca en varios sentidos. Por un lado, se trata del participante más joven de todos los que intervienen en la encuesta; si el promedio de edades ronda los 45 años, en el caso de 
Borges no supera los 30. Así lo destaca la presentación del diario: "Jorge Luis Borges, pertenece a la nueva generación". A la vez, su respuesta anticipa casi literalmente largos fragmentos de una de sus intervenciones lingüísticas más conocidas, la conferencia "El idioma de los argentinos", que Borges pronunciará unos meses más tarde, el 23 de septiembre de 1927.

Al comienzo de su respuesta, Borges busca distinguir entre deseo y posibilidad: "Yo soy un deseoso del idioma argentino - de ese idioma tan profetizado y preconizado desde Alberdi, desde Sarmiento, desde Echeverría, desde Gutiérrez- pero malicio que no basta apetecerlo con flojera para ser dueños de él”. A continuación, busca abordar la cuestión desde otro punto de vista, si se quiere técnico, en virtud del cual rechaza la posibilidad inmediata de una lengua argentina; como en las restantes respuestas, el uso de las categorías que buscan caracterizar las formas de habla resulta inestable y problemático, como en el siguiente fragmento donde Borges acumula "idioma”, "jerga" (a las que trata como equivalentes) y "vocabulario gremial" en unas pocas líneas:

En el pasado mañana, no en el mañana ni en el hoy, lo ubico a ese adivinado idioma argentino. No creo en la mucha colaboración del lunfardo ni en la de su derivación, el arrabalero. El lunfardo es una jerga artificiosa de los ladrones, es un vocabulario gremial tan especializado -es decir, tan sin empleo fuera de su especialidad- como el de los carpinteros o el de los vareadores. [...] El arrabalero es una simulación del lunfardo, es una mezcla de lunfardo trasnochado y de habla vulgar.

Los dos -arrabalero y lunfardo- son tan exiguos que los que versifican en ellos tienen que invertir las palabras a cada rato para decir las cosas de un modo que no sea demasiado corriente. El vesre es la evidencia de la pobreza confesadísima de esos dialectos.

Hacia el final, reconduce el problema hacia el plano del deseo; en esa dimensión, la búsqueda de una lengua propia es ante todo un mandato estético, una posición que encontrará su ampliación en "El idioma de los argentinos" y que hemos analizado en detalle en otro trabajo (Degiovanni y Toscano y García 2010a):

Sin embargo, creo en el idioma argentino. Creo que es deber de cada escritor (nuestro y de todos) el aproximarlo. Para ese fin, nos basta considerar el español como una cosa apenas bosquejada y muy perfectible. Sintamos todos esa urgencia de innovación, sintámonos vivir en América y ya estará iniciada nuestra aventura. Digamos cosas que no le queden chicas a Buenos Aires y hablaremos idioma nuevo que será nuestro.

La respuesta de Manuel Gálvez es, en general, criteriosa; como pocos de los entrevistados, busca identificar los fenómenos que distinguirían el español usual de la Argentina del que se habla en la Península, y encuentra que se trata de diferencias en general de pronunciación que no afectan a la lengua escrita:

No creo que lleguemos a tener alguna vez un idioma propio. Hasta hoy no se advierte ninguna diferencia entre el castellano de España y el nuestro. Es cierto que no distinguimos entre la "ese", la "ce" y la "zeta”, y que damos a la "y" y a la "elle", frecuentemente, un sonido semejante al de la jota francesa; pero esto ocurre en el hablar, pues cuando escribimos no confundimos estas letras. Además, en Andalucía y en otras regiones españolas también se ha suprimido, en la conversación los sonidos castizos de la "ce" y la "zeta".

Por lo demás, su respuesta abreva en los tópicos que ya hemos reconocido en las intervenciones previas: función unificadora y normalizadora de la escuela y de los escritores argentinos, infantilización del deseo de una lengua propia ("La enemistad contra el buen castellano es cosa de los veinte años, y más me parece un recurso defensivo de la ignorancia juvenil que un sentimiento") y caracterización del lunfardo como un fenómeno parasitario análogo al que ocurre en otras lenguas ("En cuanto a la intromisión del llamado 'lunfardo' en el lenguaje corriente, es un hecho sin importancia filológica. En todos los países del mundo existe un argot: uno o varios").

En un contexto en el que, como hemos señalado al comienzo, ha emergido y se ha consolidado un campo científico para los estudios lingüísticos, que entre otros aspectos ha reformulado los protocolos de legitimación, del derecho a intervenir legítimamente en cuestiones de ciencia, la colocación inicial que Enrique García Velloso hace de sí mismo como un experto en el tema de la encuesta es, quizás, una evidencia de que no ocupa ya ese lugar: 
La cuestión del castellano en América, y especialmente en la Argentina, la he tratado muchas veces en la cátedra y en el libro. Me inicié, precisamente como profesor, realizando en el Colegio Nacional de Buenos Aires una serie de conferencias, bajo el patrocinio del entonces rector don Enrique de Vedia -sobre el neologismo y el barbarismo en el idioma castellano y el vulgarismo cosmopolita derivado de la avalancha aluvial en la República Argentina.

Su posición es de rechazo: "No creo que el idioma de los argentinos sea en un futuro otro idioma que el castellano, enriquecido, aumentado, con todo lo que la vida de relación exija en un país como el nuestro". Notablemente, para García Velloso no hay siquiera un fenómeno de cambio lingüístico en curso: su diagnóstico se aleja así del que durante los años siguientes harán los filólogos españoles respecto del español hablado en la Argentina, y en particular en Buenos Aires. Para García Velloso, el español del periodismo, de la cátedra y del debate público es correcto castellano, una valoración que notablemente contradice y en relación con los mismos ámbitos la que hará Amado Alonso en "El problema argentino de la lengua" en 1932: "Nunca se ha hablado mejor el castellano entre nosotros que hoy [...]. En un país tan cosmopolita como el nuestro, nunca seremos más argentinos que cuando hablemos y escribamos el castellano correctamente".

García Velloso agrega a los anteriores otros elementos unificadores: la imprenta, en primer lugar, pero también la escuela, que actúa como fuerza contraria a la disrupción que impone la inmigración:

Cada día se escribirá mejor, se hablará mejor. Lo sé como profesor. Cuanto más babilónica se hace la ciudad, más se perfecciona el idioma por espíritu de propia conservación nacional. [...]

En mis clases he observado que los mejores alumnos de castellano son los de origen semita, ya polaco, ya ruso o alemán.

Tienen una ortografía científicamente aprendida y no, como la mayoría de los chicos valiéndose de la memoria de la vista: su prosodia se perfecciona día a día (oígase recitar a mis alumnas israelitas del Conservatorio).

Como anticipamos, Arturo Costa Álvarez es posiblemente el único de los entrevistados que podría reivindicar para sí el lugar del experto; esa es de hecho la lógica de la polémica que libra contra los filólogos del Instituto de Filología (Toscano y García 2013 y 2015). La presentación de Crítica parece confirmar esa colocación: dice que "Arturo Costa Álvarez es un erudito en la materia de esta encuesta", y también que "En numerosas revistas especializadas del país y del extranjero hace años ya que Costa Álvarez viene exponiendo sus teorías con verdadero acierto y acopio de conocimientos profundos".

Ese lugar del experto, sin embargo, parece negado por la circunstancia de que Costa Álvarez utiliza para responder a la encuesta un registro humorístico que es el mismo que el de Last Reason, con el que busca polemizar; se trata de un formato argumentativo, de unas normas de argumentación lingüistica según la caracterización hecha por Schlieben-Lange (1993) ya imposible en el modelo de ciencia impuesto por los filólogos españoles. Estas cuestiones de colocación en el contexto de la disciplina aparecen ya al comienzo de su respuesta:

El ingenioso Last Reason ha pegado una espantada de la madona al ver aparecer de pronto en su campo, como fantasmas asustadores, las figuras solemnes e imponentes de Ricardo Rojas, Víctor Mercante y Enrique Larreta. Me explico la espantada: la Majestad universitaria en la plaza pública...

La observación muestra que, si como quiere el diario, Costa Álvarez es un experto, de ninguna manera representa el lugar de la academia, que estaría asociada a esas tres figuras a las que él alude. En otros términos: puede haber todavía, al menos en un espacio periférico como el de Crítica o Nosotros, una valoración del experto como alguien que no proviene del campo universitario. En nuestra perspectiva, lo marginal de esas valoraciones da testimonio de que ya hay un proceso de constitución del campo muy consolidado.

La respuesta de Costa Álvarez busca demostrar que el orillero no es una lengua sino un "habla popular", "regional" y "local”, que parece ser lo más que cualquiera de los entrevistados puede acercarse al concepto de variedad. Sin embargo, la apreciación resulta técnicamente correcta: dice que el orillero existe, pero que no es una lengua; al mismo tiempo, que la lengua estándar es "la oficial, la escolar, la culta":

¿Quién ha negado o discutido esta rama lateral y baja del castellano, que por cierto no existiría si no sacara del tronco su substancia?... [...] No; negar el orillero sería negar el sol de Mayo... Pero ¿qué tiene que ver el orillero con el idioma nacional?... 
Vamos, vamos, Last Reason, no atropelle... La lengua de un país es la común, la oficial, la escolar, la culta; no es la síntesis imposible de sus diversas hablas populares, regionales y locales, y mucho menos es una sola de ellas.

Por otro lado, mientras que, según hemos visto, los entrevistados tienden a reconocer a la Academia por lo que perciben como una ampliación de su criterio hacia la inclusión de voces americanas y argentinas, o a limitar su importancia afirmando que el pueblo es el verdadero legislador lingüístico, Costa Álvarez introduce aquí, como en todos sus textos del período, una crítica de la tradición filológica española que representan Menéndez Pidal, Castro, Millares Carlo, Montolíu y Alonso; así, dice que "nada del catequismo, del tradicionalismo y de la rutina, que son la base secular de la gramática y del diccionario españoles o españolados". Todavía más: la independencia lingüística no tiene que ver para Costa Álvarez con la creación de una lengua propia sino con el establecimiento de instituciones propias que la regulen, con la posesión de instrumentos lingüísticos ajustados a la propia variedad:

Creo firmemente que los argentinos llegaremos a tener un idioma propio. Este idioma será el castellano; y nuestra posesión de él plena e indiscutible se realizará el día que apliquemos la altivez argentina a emanciparnos de la tutela extraña en cuanto al régimen de nuestra lengua: el día que, suficientemente preparados para ello, hagamos nuestra gramática y nuestro diccionario del castellano que hablamos y escribimos.

La intervención de Alberto Nin Frías, que responde desde "el punto de mira de un profesor de lenguas vivas”, desarrolla la comparación entre el español y el inglés que había aparecido sugerida en el texto de Lima. Al respecto, Nin Frías valora positivamente el proceso de independencia lingüística que ve en el inglés de los Estados Unidos, pero duda de que el proceso pueda replicarse en la Argentina debido a la diferente composición espiritual de su población, un diagnóstico que lo aproxima a la ensayística del ser nacional que desarrollarán autores como Ezequiel Martínez Estrada:

La pobreza espiritual de nuestro medio no da para un lenguaje así majestuoso ni en extremo florido; el ambiente bonaerense es de recia lucha por el dinero y sus derivados; pero también producto de una compenetración asaz dificultosa de psicología tan opuesta como ser las razas hipanas e itálicas [...]. Agréguese a este entre-choque de dos pueblos con ciertas afinidades raciales, el aluvión ruso-judío, polaco-judío, inglés, alemán, sirio, turco, francés, nacionalidades que también ejercen su presión para constituir en nuestro país, una jerga internacional hispanizante, cosa que resulta ser precisamente nuestro "lunfardo", tan artísticamente manejado por Last Reason [...].

Para Arturo Cancela, como antes por ejemplo para Rojas, la extensión de una lengua es medida de su valor; es el argumento que valora positivamente la comunidad lingüística de la que participan los hablantes del español, en una clave que es alternativamente espiritual y comercial ("material”, para Cancela):

Un idioma es tanto más interesante cuanto mayor es el ámbito de gente humana que alcanza. Nosotros por medio del español nos podemos entender con todos los pueblos del mismo origen histórico que el nuestro, pueblos que están en el comienzo de su desarrollo material y espiritual y en consecuencia el porvenir del idioma castellano es enorme.

Cancela se declara incapaz de abordar el tema desde un punto de vista científico; en rigor, declara que la ciencia no puede dar una respuesta definitiva a la pregunta de cómo habrá de evolucionar el castellano en la Argentina. Sin embargo, rechaza la existencia de un proceso de cambio en curso; y, todavía más, señala que existe una tendencia general, al menos en la lengua literaria, hacia la unificación con la norma peninsular:

Y hasta ahora no hay ningún signo visible que permita suponer que el idioma que hablamos en nuestra tierra llegue a tener un desarrollo distinto al que se opere en otros países de ascendencia hispánica. Por el contrario, la evolución realizada por la literatura argentina en el medio siglo último ha señalado un ligero acercamiento hacia las formas académicas.

El escritor encuentra una evidencia de este acercamiento en el hecho de que los diarios usen la variedad peninsular: "Nuestros grandes diarios ya no emplean, por ejemplo, los términos papas por patatas, vereda por acera, motorman por motorista"; el argumento que remite al papel normalizador de la prensa escrita es recurrente en la encuesta, y (repetimos) caracteriza una situación muy distinta de la que Alonso primero y Castro después describirán en sus trabajos de la década del treinta y comienzos del cuarenta. 
Finalmente, Cancela percibe un aspecto del problema que ningún otro de los encuestados registra: el hecho de que la dinámica del cambio lingüístico es distinta en la ciudad y en el interior del país; su reclamo de un "estudio geográfico" de las variedades del español de la Argentina resulta sumamente moderno si se tiene en cuenta que habrá que esperar hasta 1930, con la creación por parte del Instituto de Filología de la Biblioteca de Dialectología Hispanoamericana (Toscano y García 2014), de un primer intento de descripción de las variedades dialectales del español de la Argentina:

Y para hablar sobre castellano en la Argentina no hay que atenerse a la jerga más o menos libre que empleamos en Buenos Aires sino al castellano pintoresco y a ratos arcaico que se habla en Salta, en Jujuy, en La Rioja, etc.

Un estudio geográfico de esta cuestión permitiría afirmar con mucha probabilidad que en conjunto nos hemos apartado menos de las formas prístinas del castellano que el propio pueblo de la península.

La respuesta de Alberto Gerchunoff no aporta elementos novedosos respecto de los que ya hemos relevado; para él, lo que se busca elevar a la categoría de "idioma propio" es un fenómeno restringido al ámbito urbano, un uso "pintoresco". Esos fenómenos de variación, señala, son comunes en todas las lenguas, y “[c]reer que vamos a tener una lengua original basándose en estos rasgos, es como si los franceses creyeran que su lengua será distinta en el futuro, tomando por punto de partida la difusión del argot parisién”. Por otra parte, si Payró asimilaba la pretensión de una lengua propia a un berrinche infantil, Gerchunoff encuentra que quienes pretenden una lengua propia son aquellos que no consiguen hablar correctamente el español general:

Finalmente, eso de reformar el idioma para argentinizarlo sería como pretender modificar la estructura de la guitarra, que también la hemos heredado de España, a fin de que los que la tocan estén en mejores condiciones para disimular su deficiencia de ejecutantes. Me parece mucho más fácil aprender a tocar la guitarra...

La presentación que Crítica hace de José María Moner Sans parece colocar al diario al lado del normativismo correctivo de Monner Sans (padre): “José María Monner Sans es un estudioso que domina el tema de esta encuesta”. Dice de él también que prepara "varios trabajos filológicos, dignos de figurar al lado de las obras de quien contribuyó tan acertadamente a depurar el uso del castellano entre nosotros".

Monner Sans repite varios de los argumentos desplegados hasta aquí para rechazar la posible formación de un idioma propio; es el único hasta aquí (luego lo hará Garrigós), sin embargo, que nombra explícitamente a Abeille como figura emblemática de las posiciones independentistas:

Estando la evolución o transformación de un idioma sujeta a leyes naturales, no es cosa de que, porque sí, en una rueda de chicos, se proceda a inventar una nueva lengua.

Si el castellano va a tomar, entre nosotros, una entonación especial, ese matiz lo ofrece ya en diversas regiones de la misma península. Por esto, las tentativas trasnochadas y olvidadas como la de Abeille, posiblemente fueron ideadas para halagar la vanidad criolla.

Por lo demás, Monner Sans descalifica cualquier pretensión de independencia lingüística; apela también a la infantilización del reclamo, o a situarlo, como antes Gerchunoff, como propio de ignorantes: "Creo que más que cultivar una lengua propia, lo interesante sería hablar bien el español, aunque fuera una sola vez en la vida y mediante algún esfuerzo...". Su compendio de censuras incluye al lunfardo ("Lo repudiable y de mal gusto es la formación del lunfardo, idioma del delito que, por rara coincidencia, aparecen hablando hasta las clases aparentemente cultas") y hasta el vesre: quienes los usan muestran la limitación de sus capacidades mentales, una valoración que le valdrá a Monner Sans la célebre respuesta de Arlt en su aguafuerte "El idioma de los argentinos" (1930):

Respecto a la jerga al revés, que tanto se emplea entre nosotros, lejos de probar ingenio, demuestra una desconsoladora pobreza de espíritu. Dicha jerga, unida al lunfardo, forma el modo habitual de conversar de gentes de todas las clases sociales sin excepción, lo que, por otra parte, sirve para definir la categoría mental de cada uno, porque nunca es tan verdadero como en estos casos aquello de que, "según se habla así se es". 
Florencio Garrigós (hijo) es el último de los entrevistados; es, como Costa Álvarez una figura desplazada del centro del campo científico, que los gramáticos escolares habían ocupado largamente durante al menos el último cuarto del XIX y las primeras décadas del XX.

Como Cancela, Garrigós responde retrocediendo el problema: dice que en verdad no hay señal ninguna de cambio, que allí donde los otros ven ruptura él ve continuidad. Para ello introduce una distinción pertinente, que recupera la de Larreta, entre lengua culta y lengua vulgar; y señala que, si es posible que en la lengua popular haya elementos de diferenciación, "literariamente nuestra lengua no difiere en lo más mínimo de la que cultivan con tanto esmero los españoles contemporáneos”. Para Garrigós, el idioma de los argentinos es el de los que hablan la variedad culta, y conectan de ese modo con España y el resto de América; el culto al "guirigay" (el término curiosamente, había sido usado por Costa Álvarez en el mismo sentido en 1922) es propio de los sectores vulgares, cuyos usos no deben ser tenidos como representativos de la lengua de un país:

En el habla de todo pueblo, cabe distinguir dos elementos: el culto y el popular. ¿A cuál de éstos debe uno referirse cuando se habla del posible idioma de los argentinos? Con Rodolfo Lenz creo que al culto, a pesar de la opinión de filólogos que, como Américo Castro, lo consideran más bien adventicio y sin influencia en la evolución de las lenguas. Si el uso del término medio de la gente que maneja el idioma literario, esto es, el uso de la gente culta, debemos tener en cuenta para la apreciación de los hechos lingüísticos, no cabe duda que los que forman parte aquí del mundo de la inteligencia, se sienten más identificados con el elemento pensante del resto de América y de España, que con la clase que rinde culto al guirigay.

Garrigós procede luego a revisar los elementos que se identifican como evidencia de una lengua propia; rechaza así la interpretación de Abeille, pero también la de otros como Maspero, que habían clasificado como argentinismos lo que está en el español común y peninsular en particular: los procesos de cambio son comunes a todas las lenguas, sostiene Garrigós:

El cambio de género en algunas palabras, los defectos de acentuación, la mutilación de las formas verbales, las acepciones
locales que toman los términos de uso general, el surgimiento de voces indígenas o de neologismos y otras alteraciones que
se notan en el habla popular, son comunes a todos los pueblos y no pueden, por tanto, circunscribirse a nuestro país. Por
eso tiene que impresionar mal y hasta disgustarnos cuando oímos hablar por ahí del idioma de los argentinos, sin otro
fundamento serio que la existencia de unos cuantos vocablos y giros populares, destinados en su mayoría a desaparecer del
caudal de la lengua o a renovarse constantemente, por razones de gusto, de moda y hasta de capricho.

Finalmente, Garrigós introduce un argumento técnico en general soslayado por los participantes en la encuesta: dice que, incluso si se pretendiera que el habla vulgar y no la culta rige la vida de una lengua, las modificaciones sufridas por el castellano en la Argentina son circunstanciales y "afectan sólo a parte del léxico"; "y que las restantes no han conseguido alterar en forma permanente el régimen y la sintaxis castellana”. En otros términos, que si una lengua es un léxico y una gramática, los fenómenos de variación parecen circunscribirse a un conjunto acotado de fenómenos en el primero de esos niveles.

Dos días después, el 29 de junio de 1927, Crítica publica una nota editorial a modo de balance y cierre de la encuesta. Bajo el título "Terminó la encuesta de Crítica”, concluye que después de haber entrevistado a "todos los sectores literarios", desde "el gramático engolado" hasta "el escriba lunfardizante”, puede verificarse de forma "casi unánime" la opinión de que "no llegaremos nunca a tener un idioma propio". Como señalamos antes, la conclusión acierta en reconocer el rechazo mayoritario, pero obvia mencionar las respuestas positivas (como la de Last Reason) o las que se pronuncian en contra de la posibilidad pero a favor de su búsqueda.

Notablemente, el diario registra como el más destacado argumento en contra de la posesión de un idioma propio el de la pérdida de la unidad lingüística, un argumento de alcance "político y comercial":

Fuera de las indiscutibles razones artísticas, muchos han echado mano a importantes argumentos, como políticos y comerciales; un nuevo idioma nos aislaría, no solamente de Europa, sino del resto de América, pues es de presumir cuerdamente que los países hermanos no compartirían en ningún momento el artificioso vocabulario nacido en tal caso de un deseo efímero y no de una necesidad vital. 
En un texto a través del que no duda en mostrar su acuerdo con las posiciones que entiende que la encuesta ha demostrado, Crítica admite que la Academia debería ser más sensible a la incorporación del léxico extrapeninsular ("Todos están de acuerdo, por otra parte, con la incorporación necesaria de los vocablos típicos, americanismos, argentinismos, etc., al diccionario de la Real Academia adquiriendo así carta de ciudadanía"), pero no del lunfardo, del que dice que "ha sido, pues, ampliamente derrotado". Pero, sobre todo, rechaza de plano la posibilidad de que los fenómenos de variación que se registran en el español de la Argentina sean rasgos de una nueva lengua:

Y, finalmente, algunos han llegado a conceder que el castellano en la Argentina llegue a adquirir un tono diferencial sin perder su naturaleza primitiva, al contrario de otros -los menos- que no han trepidado en afirmar que aquí se habla el español mejor aun que en el país de origen.

Mostrar esa identidad ha sido, se congratula el diario, uno de los principales méritos de la encuesta, tanto como el de confirmar "que existen en el país hombres empeñados en velar por la pureza y la salud del idioma".

\section{CoDA}

El 25 de septiembre de 1927, casi tres meses después de finalizada la encuesta, Crítica vuelve sobre el tema con un artículo titulado "La encuesta de Crítica: ¿Llegaremos a tener idioma propio? y D. Américo Castro"; se trata, en rigor, de la respuesta editorial del diario a un artículo que Américo Castro había publicado una semana antes en La Nación, con el título "En torno al posible idioma argentino".

En ese texto Castro, habitual colaborador de La Nación desde su gestión al frente del Instituto de Filología en 1923, vuelve sobre algunos de los temas que había abordado en artículos previos (por ejemplo en Castro 1924), y en particular sobre el de la eventual existencia de una lengua nacional, a partir esta vez de la encuesta realizada por Crítica, a la que alude muy indirectamente. Ese texto de Castro es un trabajo decisivo en su producción porque allí, a diferencia de los textos anteriores en los que había abordado la cuestión desde un punto de vista más estrictamente lingüístico y procurado ofrecer una descripción técnica del fenómeno de la variación, construye una teoría de lo nacional que amplía la carga valorativa y la clave de interpretación histórica que será el marco general interpretativo que propondrá en La peculiaridad lingüistica rioplatense y su sentido histórico(1941).

En este trabajo, Castro propone detenerse y ocuparse de un "hecho de marcado cariz americano: el deseo de poseer un lenguaje propio" (1927: 4). Verifica la existencia de ese fenómeno en Estados Unidos (donde "el problema del idioma propio no preocupa al norteamericano"), en Brasil (donde la intención es distanciarse de Portugal; una pretensión tan legítima como lejana, para Castro) y, en Argentina, en "el fracasado libro de Abeille El idioma nacional, y de vez en cuando en la prensa, como acontece en la encuesta a que vengo aludiendo" (1927: 4). Para Castro, que se muestra paternalista en relación con las jóvenes repúblicas americanas, el deseo de una lengua propia es, moderadamente, expresión de un noble espíritu de crecimiento autónomo de los países menos desarrollados.

Sin embargo, en Argentina, señala Castro, el problema ha sido históricamente mucho más importante que en otros países. Si bien se ha superado desde hace tiempo la idea de que un país independiente necesita una lengua propia, y su literatura va consiguiendo cada vez mejores productos, a partir fundamentalmente de la actividad de diarios y revistas, sin embargo existen también actitudes más heterogéneas y contradictorias, que todavía proponen, contra lo que va siendo norma, ideas de independencia lingüística. Esto se debe, según Castro, a razones de tipo histórico y social. Estas, por otro lado, señalan que la reivindicación de la diferencia lingüística es parasitaria, reaccionaria y antimoderna: "La amalgama de razas, la distinta altura de los niveles del pensamiento colectivo, el popularismo hereditario, todo determina o favorece la aparición del anacronismo ideológico, al lado de las formas normales del progreso rápido y seguro" (1927:4). La afirmación de la existencia propia y peculiar aparece entonces como un reclamo absurdo producido por una confusa 
serie de razones en la que se mezclan la presunta heterogeneidad racial en la composición de la población argentina, la intervención de las clases populares y menos cultas en el debate, la tradición populista a nivel político y un espíritu de retroceso en materia de desarrollo.

A continuación, ofrece una rápida refutación de ese absurdo; se trata del único párrafo estrictamente lingüístico del artículo, y Castro procura nuevamente demostrar que la lengua nacional argentina no es otra cosa que la incorporación de algunos vulgarismos, deformaciones y términos del lunfardo:

¿Con qué vamos a cargar nuestro propio deseo de una lengua propia? ¿Con lunfardismos y giros del arrabal porteño? ¿Dónde está su peculiaridad? Creen que diciendo "davi” y no "vida" se hace una lengua; también los jaques de Quevedo dicen "greno" para no decir "negro". Piensan que es un magnífico porteñismo la frase "me cach'en dié", cuanto todo el mundo sabe que eso es un vulgar eufemismo de la grosera execración de la divinidad, conocido por los setenta millones de hispanohablantes (1927: 4).

A diferencia de lo que serán sus posiciones de 1941, aquí Castro parece minimizar la "peculiaridad" lingüística argentina, acudiendo para ello a la estrategia de mostrar que esta se ha construido eventualmente a partir de elementos lingüísticos secundarios, no constitutivos, propios de las formas de los sectores menos cultos, y además existentes en otras variedades del español. Así, dice, reivindicar fenómenos como los anteriores es un retroceso que implica volver a lo menos valioso de la tradición hispánica; un fenómeno responsable de lo peor de España y América, que registra por igual en las Cortes de Carlos IV y Fernando VII y en el gobierno de Juan Manuel de Rosas; lo que, citando a Francisco Giner de los Ríos, "el máximo educador que hayamos conocido", constituye el mal de España, "el gusto por el guiñapo”. La impugnación así se vuelve extensiva a España y América, que se igualan por la barbarie y en el rechazo que Castro hace del habla vulgar: "Jacarandina, germanía, majeza, chulería, orilleros, compadritos: ya hace unos siglos que sabemos sus encantos" (1927: 4). Así, finalmente, lo que sería un deseo legítimo (es decir, una voluntad de independencia propia de las nuevas naciones), para Castro se sostiene sin embargo en "los espectros del provincianismo y del plebeyismo"; hablar de un idioma argentino, dice, responde a una concepción provinciana del problema lingüístico y es un gesto que se opone a la modernización y el desarrollo que caracterizan a una república pujante como la Argentina. En lo esencial, como decíamos, estos planteos serán recuperados y ampliados en La peculiaridad lingüistica rioplatense y su sentido histórico.

La respuesta de Critica se articula en dos niveles. En primer lugar, señala (correctamente) que Castro responde a la encuesta aunque sin referirla explícitamente:

En el suplemento literario de nuestro colega La Nación del último domingo el eminente gramático y filólogo Américo Castro escribe pulcramente, como él sabe hacerlo, en torno al posible idioma nacional de los argentinos. Sin nombrar a Crítica, se ve a las claras que su sesuda digresión ha sido motivada por la encuesta que hiciera nuestro diario a mediados del año corriente.

A continuación, el texto hace una intervención de naturaleza muy distinta de la que había ofrecido en la encuesta; ya no recoge la opinión de expertos sino que editorializa largamente sobre el tema objeto de debate. El sentido de esa intervención parece ser el de responder al texto de Castro, con el que sin embargo acuerda en muchos de los aspectos centrales; lo singular en cualquier caso es que el diario destine un largo artículo a sentar su posición en relación con la cuestión del idioma nacional.

El trabajo comienza estableciendo que existen en cualquier sociedad dos hablas, una culta y otra popular; en este sentido, afirma, el arrabalero es similar a otras hablas populares que se hallan en otras partes del mundo, y de ninguna forma constituye el embrión de una nueva y futura lengua. La valoración de estas hablas, a diferencia sin embargo del texto de Castro, no es abiertamente negativa; la distinción parece, en el planteo de Crítica, puramente moral:

Por más que busquen los doctos y las clases cultas, o simplemente adineradas, inspirarse en la cultura idiomática hispana, siempre existirá, cabe el lenguaje correcto, estilizado y formal, el idioma del coloquio íntimo, flor del terruño y de la originalidad circundante. 
Todo pueblo cuenta con estas dos fases lingüísticas, y no cabe imaginar que esta sociabilidad, todavía tan plástica, no reproduzca los mismos fenómenos que se originan en Londres, París, Madrid, donde se habla el "cockney", el "argot" y el "chulo", respectivamente. Nuestra lengua arrabalera tiene el mismo significado de estos lenguajes convencionales, creados por el cabaret, el hampa, el burdel y la vida de los placeres tumultuosos en general.

Si la valoración de esas hablas populares difiere de la de Castro, sin embargo hay coincidencia en la cuestión de fondo, que busca negar que exista en ellas un germen, una protolengua: "erigir esta forma verbal en base para una nueva lengua del porvenir, de genuino cuño nacional, es cosa en la cual nadie ha pensado seriamente aun”.

Pero lo más interesante de la intervención de Crítica es la evaluación que hace con argumentos "técnicos" de la pretensión de una lengua propia: en este contexto de reconfiguración epistemológica propio de la emergencia de un campo científico, resulta notable que el especialista -Castro- abandone el planteo disciplinar y el periódico - Crítica- sostenga en cambio una perspectiva moderna desde el punto de vista del saber lingüístico contemporáneo, un punto de vista que tendrá su modelización más clara en los desarrollos que Alonso hará hacia fines de la década siguiente, y que en lo esencial reconfiguran la discusión acerca de la variación lingüística a partir del establecimiento del axioma de que las lenguas son inherentemente variables. Ese planteo, que aparece sin embargo también en la lingüística no académica del período (por ejemplo, según hemos demostrado, en Vicente Rossi; véase Toscano y García 2013 y 2016), constituye quizás el planteo más audaz de toda la encuesta, y sin embargo no proviene de ninguno de sus entrevistados:

Creemos que este vago anhelo del idioma propio -aspiración que, desde luego, cuenta con muy escasos partidarios autorizados [...]- radica en un axioma fundamental de la ciencia lingüística: la historia, proceso de evolución del idioma, jamás se detiene: deviene mientras existe el pueblo que le haya dado existencia. $\mathrm{O}$, dicho en otra forma: el proceso formativo del castellano es hoy tan activo, como en los días de Alfonso el Sabio. Más aún: los factores de estos cambios son actualmente del mismo carácter que lo fueron en las épocas más remotas, e idéntica suerte de fenómenos son observables en el actual proceso, como acaeció al idioma castellano en el pasado.

Si este texto de Crítica destaca por su carácter excepcional de intervención editorial sobre cuestiones lingüísticas tanto como por su capacidad para plantear algunas de las cuestiones centrales de la lingüística contemporánea, también lo hace el texto que el diario publica al día siguiente, 26 de septiembre de 1927, con el título de "En Buenos Aires se habla bien el español. El diario, el libro y el puerto son enemigos del lunfardo, nos dice el filólogo español Amado Alonso". Del pulso del diario para identificar los debates culturales del período da prueba aquí el hecho de que, en la misma página y a la izquierda, Crítica recoge bajo el título de "Madrid, meridiano intelectual de Hispanoamérica" otro de los debates centrales de ese año.

La presentación que el diario hace de Alonso lo coloca a las claras en el lugar del experto:

Contratado por la Facultad de Filosofía y Letras para dirigir el Instituto de Filosofía, ha llegado recientemente a Buenos Aires el profesor español Amado Alonso, quien se propone realizar una serie de estudios que serán de interés, sobre argentinismos y formas usuales de nuestra conversación.

Ese plan de investigación que el diario anuncia contrasta con el tipo de trabajo que, según hemos mostrado (Toscano y García 2009, 2013), el Instituto de Filología venía llevando a cabo desde su inauguración en 1923 y todavía llevará a cabo durante buena parte de la gestión de Alonso: un tipo de trabajo que se concibe en lo esencial como una continuidad, con matices, del trabajo llevado a cabo en Madrid por el Centro de Estudios Históricos dirigido por Menéndez Pidal.

No obstante lo anterior, Alonso asume el lugar de afirmación del experto, y coloca su análisis del fenómeno de la eventual existencia de una lengua nacional bajo una perspectiva que él mismo califica de científica, es decir neutral, ajena a la lógica sentimental del nacionalismo y que inscribe en un horizonte de conocimiento que funcionaría como respaldo y legitimación:

Para un argentino no especialista, el problema de la formación de un nuevo idioma tiene los mismos contornos limitadores de su propio mapa nacional. Para un especialista, y más si viene de fuera de modo que no pesen sobre su criterio preocupaciones 
extracientíficas, el problema del nacimiento de lenguas es mucho más general. Conocemos bien las condiciones propicias a la formación de nuevas lenguas, como asimismo las razones que tienen función de frenos en el movimiento de los idiomas. Todo hace pensar que la aparición de nuevas lenguas es fenómeno casi imposible en la sociedad moderna. De modo análogo, los geólogos consideran ya como definitiva la presente configuración de la corteza terrestre, a pesar de los complejos y gigantescos cambios sufridos en edades anteriores.

Respecto de la autoridad de legislar sobre la lengua, para Alonso se observa un proceso según el cual las repúblicas americanas comienzan a igualarse a España;

Me importa hacer constar [...] que la explicación anterior supera la general creencia de que las repúblicas americanas han de estar en dictatorial dependencia idiomática de España. Hasta ahora por razones obvias, España ha tenido la ventaja decisiva de su larga y gloriosa tradición cultural. Pero el nivel de cultura en Hispano-América, muy en especial en Chile y en el Río de la Plata, va alcanzando rápidamente la altura europea. La consecuencia debe ser la sustitución del estado de dependencia por el de independencia. Y esto de ningún modo por gestiones de fisonomía diplomática, ni por legislación académica. Las Academias no podrán hacer más que sancionar, en el terreno del idioma, los fenómenos sociales consumados.

En relación con el lunfardo (al que Alonso califica de "argot"), el pronunciamiento es fuertemente valorativo y negativo; sin embargo, el argumento técnico parece razonable:

La cuestión del lunfardo [...] tiene un doble aspecto que es necesario desdoblar. Por un lado, sus caracteres específicos, por otro su aceptación social. Como yo no he hecho ninguna investigación personal, sobre esta modalidad, no podré dar una opinión nueva. El lunfardo, por sus caracteres intrínsecos da la impresión de un habla de campamento, con numerosos elementos lexicales de aluvión, pero respetando en absoluto la estructura interna de la lengua que los acoge. El procedimiento de la mutilación de palabras y de la inversión de sílabas es común a los argots de cualquier otra gran ciudad cosmopolita.

En cuanto a la aceptación social del lunfardo, notablemente Alonso acude a la propia encuesta del diario Crítica como cita de autoridad que le permite rechazar su legitimidad:

En cuanto a la aceptación social, no seré yo quien pueda informar. Reciente está la encuesta de Crítica. Las formas jergales en otras partes tienen una importancia mínima, porque sufren la absoluta repulsa de las clases cultas. Una de esas formas limitadas al estrecho recinto de una clase de personas, poco o nada influyentes en la vida nacional, tiene vida raquítica. Pero aquí hay una atención simpatizante, bastante extensa, para esas formas jergales. En esto sí que el lunfardo difiere de todos los argots conocidos.

[...] De aquí que el futuro triunfo del lunfardo esté en manos de los mismos argentinos. Pero, según se ve por la misma encuesta, me parece que no sucederá tal cosa. Fuera de algún escritor colorista que utiliza esa modalidad como instrumento de trabajo, los argentinos de alta cultura, se han manifestado en contra.

Esa valoración positiva, esa confianza en los datos que para él la encuesta de Crítica ofrece le permite a Alonso, que lleva menos de un mes en Buenos Aires, establecer sin embargo un diagnóstico contundente sobre la calidad del habla porteña:

Buenos Aires es una ciudad donde se habla bien el español [...]. Si tomamos como español tipo el que se oye, por ejemplo, en las comedias y dramas que representa la compañía de María Guerrero, podríamos comprobar en abundancia que los porteños de cultura media hablan una lengua mucho más conforme con el español tipo que los españoles de cultura media de las regiones que circundan Castilla. Y en las clases bajas, a pesar del lunfardo, los apartamientos peninsulares son mucho más hondos.

Este diagnóstico, según el cual los sectores medios y bajos hablan un “español tipo” mejor que el de esos mismos sectores españoles, será rápidamente desmentido por uno de los textos menos felices del filólogo español, el que publica en 1932 en la revista Sur y que tiene como objetivo denunciar lo que se representa como la corrupción del habla porteña, especialmente de sus sectores medios y altos.

\section{Conclusiones}

Sztrum (1998: 220) señala que "Crítica [...] ya había recogido opiniones polémicas sobre el idioma nacional; pero casi exclusivamente en lo que hace al lunfardo, tema lingüístico de predilección del vespertino desde 
sus comienzos" ${ }^{6}$. De alguna manera, puede entenderse que la sola opción por la encuesta como mecanismo de indagación es testimonio del tipo de situación del que la encuesta participa: el criterio de la mayoría, puede pensarse, no es (no necesariamente es) el criterio de la ciencia. La encuesta supone que no hay una palabra autorizada; en términos de Bourdieu, que no hay un monopolio de la autoridad científica; ello es consistente, como dijimos, con el hecho de que el proceso de conformación de un campo científico está en curso, y en particular con que la institución que encarna ese proceso se encuentra virtualmente acéfala, ya que al momento de la encuesta no tiene director, cargo que ocupará Alonso solo unos meses después. Al mismo tiempo, el mecanismo de la encuesta dice respecto de los encuestados, que si participan de ella de alguna manera validan el supuesto de que no existe un recurso a la verdad de la ciencia que puedan enunciar como indudable. Finalmente, es necesario registrar que el conjunto de participantes a los que Crítica da la palabra muestra su decisión de oponer a ese campo científico a la vez emergente y acéfalo todo un mapa complejo de un campo cultural que, incluso si periférico respecto del saber ahora experto, conserva indudablemente su densidad conceptual.

Por otro lado, esperamos haber demostrado que la frontera entre las intervenciones profesionales y las que no lo son no puede demarcarse en función del espesor teórico de las respuestas ofrecidas; así, por ejemplo, hemos registrado en las respuestas dadas por los no expertos argumentos que provienen del saber experto; al revés, hemos mostrado que algunas de las intervenciones debidas a los no especialistas, y en particular la nota editorial final del diario Crítica, prefiguran algunos de los desarrollos teóricos que los lingüistas profesionales desarrollarán durante los años siguientes. La distinción entre unos y otros, entonces, parece vincularse con otros aspectos: por una parte, por los formatos textuales por los que optan, las normas de la argumentación lingüística a las que nos hemos referido. Por otra y posiblemente más significativa parte, al modo en que se representan el problema de la encuesta. Así, mientras que el saber técnico de los filólogos españoles parece aislar la cuestión como un problema puramente lingüístico, la mayor parte de los entrevistados la aborda como un problema estético. Esta distinción, creemos, no debería ser perdida de vista a la hora de analizar el modo en que se articulan los debates sobre la lengua durante las primeras décadas del siglo pasado.

\section{ReFERENCiAS}

Abeille, L. [1900] (2005). Idioma nacional de los argentinos. Buenos Aires: Colihue/Biblioteca Nacional.

Alfón, F. (2011). La querella de la lengua en la Argentina (1828-1928). (Tesis doctoral), Universidad Nacional de La Plata, La Plata, Argentina.

Alonso, A. (1932a). El problema argentino de la lengua, Sur, 6. 124-178.

Archivos de la Universidad de Buenos Aires (1927). Buenos Aires: Universidad de Buenos Aires.

Bourdieu, P. [1976] (2000). El campo científico. En Los usos sociales de la ciencia. Buenos Aires: Nueva Visión.

Castro, A. (1924). ¿Dialecto argentino?. En La Nación. 20 de abril de 1924. 4.

Castro, A. (1941). La peculiaridad lingüistica rioplatense y su sentido histórico. Buenos Aires: Losada.

Conde, O. (2017). El 'Novísimo diccionario lunfardo' en la página de policiales de Crítica (1913-1915). Un folletín a pura literatura. En O. Conde (ed.), Argots hispánicos. Analogias y diferencias en las hablas populares iberoamericanas. Remedios de Escalada: De la UNLa - Universidad Nacional de Lanús.

Costa Álvarez, A. (1922). Nuestra lengua. Buenos Aires: Sociedad Editorial Argentina.

Degiovanni, F. y Toscano y García, G. (2010a). 'Las alarmas del doctor Américo Castro': institucionalización filológica y autoridad disciplinaria, Variaciones Borges, 30. Pittsburgh. 3-42.

Degiovanni, F. y Toscano y García, G. (2010b). Disputas de origen: Américo Castro y la institucionalización de la filología en la Argentina, Nueva Revista de Filología Hispánica, LVIII, 1. México, 191-213.

Delgado, V. (2006). El nacimiento de la literatura argentina en las revistas literarias: 1896-1913. (Tesis doctoral), Universidad Nacional de La Plata, La Plata, Argentina. 
Di Tullio, Á. (2003). Politicas lingüisticas e inmigración. El caso argentino. Buenos Aires: EUDEBA.

Ennis, J. A. (2008). Decir la lengua. Debates ideológico-lingüisticos en Argentina desde 1837. Frankfurt et al.: Peter Lang. Ennis, J. A. (2014). El uso, la propiedad y el valor en el debate de la lengua americana, Anclajes 18: 1. 17-34.

Ennis, J. A. (2015). La propiedad y la lengua en la emergencia de los estados hispanoamericanos. Notas sobre Andrés Bello, Romanistisches Jabrbuch 65: 1. 221-249.

Ennis, J. A. (2017). La lengua al filo del siglo: las polémicas por el futuro del español de América en torno al 1900. En Anuario de glotopolitica, Buenos Aires: Cabiria. 197-228.

Glozman, M. y Lauría, D. (2012). Voces y ecos. Una antología de los debates sobre la lengua nacional (Argentina 19002000). Buenos Aires: Cabiria.

Lidgett, E. (2013). Apuntes sobre el problema de la lengua nacional en la gramática escolar argentina. En D. Lauría y M. Glozman (eds.), Lengua historia y sociedad. Apuntes desde diversas perspectivas de investigación lingüistica, 33-43. Buenos Aires, Sociedad Argentina de Lingüística. Mendoza: Editorial FFyL-UNCuyo y SAL.

Lidgett, E. (2015). El Diario Español y el debate sobre la enseñanza del castellano en la Argentina (1927-1928), Circula: revue d'idéologies linguistiques 1. 69-86.

Menéndez Pidal, R. (1918). La lengua española, Hispania I: 1. 1-14.

Oliveto, M. (2010). La cuestión del idioma en los años veinte y el problema del lunfardo: a propósito de una encuesta del diario Crítica, Revista Pilquen XII: 13. 1-9.

Oliveto, M. (2014). El problema de la lengua literaria: disputas y condiciones de transformación en la Argentina de 1920. (Tesis doctoral), Universidad Nacional de La Plata, La Plata, Argentina.

Oliveto, M. (2016). La lengua literaria en la Argentina de 1920. Buenos Aires. Recuperado de: https://www.teseop ress.com/lengua.

Saítta, S. (1998). Regueros de tinta. El diario Critica en la década de 1920. Buenos Aires: Sudamericana.

Schlieben-Lange, B. (1993). História da lingüística e história das línguas. História do falar e história da lingüistica. Campinas: Editora da UNICAMP. 35-63.

Sztrum, M. (1998). ¿Llegaremos a tener un idioma propio? Encuesta en el diario Critica, Buenos Aires, 1927, América: Cahiers du CRICCAL. Polémiques et manifestes aux XIXe et XXe siècles en Amérique latine. 21. 219-225.

Torre, G. de (1927). Madrid, meridiano intelectual de Hispano-América, La Gaceta Literaria, ibérica, americana, internacional. Letras, artes, ciencia. Periódico quincenal (1 y 15 de cada mes). I: 8. 1.

Toscano y García, G. (2005). Entre la lengua y la historia. Posiciones de Américo Castro frente a la variedad argentina del español. (Tesis de maestría). Consejo Superior de Investigaciones Científicas, Madrid, España.

Toscano y García, G. (2009). Materiales para una historia del Instituto de Filología de la Universidad de Buenos Aires (1920-1926), Revista Internacional de Lingüistica Iberoamericana, VII, 13. 113-135. Madrid/Frankfurt. ISSN: $1579-9425$.

Toscano y García, G. (2013). Linguistics and Language Change in Argentina in the First Half of the 20th Century. En J. del Valle (ed.). A Political History of Spanish. The Making of a Language. Cambridge: Cambridge University Press. 212-228.

Toscano y García, G. (2013). Materiales para una historia del Instituto de Filología de la Universidad de Buenos Aires (1927-1946), Filología XLV (2013), 143-172.

Toscano y García, G. (2014). Hacia una historia de la lingüística en la Argentina: la Biblioteca de Dialectología Hispanoamericana (1930-1949). En S. Archimbault, J-M. Fournier y V. Raby (eds.). Penser l'histoire des savoirs linguistiques. Études épistémologiques, historiques et linguistiques en hommage à Sylvain Auroux. Lyon: ENS Éditions. 453-463.

Toscano y García, G. (2015). 'Antes que mentir exclusividad que no siento'. Saberes lingüísticos e instituciones reguladoras en Delfina Molina y Vedia, Estudios de Lingüistica del Español 36. 25-56.

Toscano y García, G. (2016). Debates sobre la lengua e institucionalización filológica en la Argentina durante la primera mitad del siglo XX. En J. del Valle (ed.). Historia politica del español. La creación de una lengua. Madrid: Editorial Aluvión. 245-265. 


\section{Notas}

1 Como es sabido, la realización de encuestas fue una práctica habitual del diario Crítica durante la década del veinte; algunas de las anteriores a la que aquí se aborda tienen los siguientes temas: “¿Por qué es verdaderamente malo el teatro nacional?”; “¿Debe reformarse la ley de servicio militar obligatorio?”; “¿Existe una ciencia médica argentina?”. El trabajo decisivo de Saítta (1998) ofrece una relación del conjunto de encuestas realizadas; remitimos a él en relación con este tema y, en general, para un abordaje integral y exhaustivo del diario Critica. Respecto de la encuesta como mecanismo de intervención cultural, el trabajo de Delgado (2006), aunque referido a las encuestas de Nosotros, es esclarecedor.

2 En relación con este problema en el ámbito de la enseñanza de la lengua, véanse Lidgett 2013 y 2015.

3 Para aligerar las referencias, y considerando que ninguna de las intervenciones supera la extensión de una página, prescindiremos en lo que sigue de otra referencia que la que aquí se ofrece.

4 Los trabajos de Oliveto $(2010,2014,2016)$ constituyen junto con el de Sztrum (1998) referencias ineludibles en el abordaje de la encuesta de crítica, aunque desde perspectivas y en relación con problemas diferentes de los que aquí se abordan. Remitimos a ellos para un detallado análisis de los participantes en la encuesta.

5 En todos los casos de cita directa, optamos por transcribir las intervenciones de los participantes en la encuesta sin alterar la versión original, incluso si se trata de erratas evidentes.

6 Sobre Critica y el lunfardo, Conde (2017) es también una referencia decisiva. 